\title{
Angelman (happy puppet) syndrome in a girl and her brother
}

\author{
J A FISHER, J BURN, F W ALEXANDER, AND D GARDNER-MEDWIN
}

From the Department of Child Health, and Regional Genetics Advisory Service, Newcastle upon Tyne NE2 $4 A A$.

SUMMARY We report a girl aged 11 and her brother aged five, both with the typical features of Angelman syndrome, and three isolated cases. This report, together with a review of published 0 reports and contact with previous authors, has revealed a total of 41 sibs of probands, although only nine of these are known to have been later born. The possible effect of voluntary restriction? of family size after the birth of an affected child is discussed in relation to the possibility of auto- $\bar{z}$ somal recessive inheritance, but a recurrence risk of $5 \%$ is appropriate for use in the genetic clinic.

In 1965, Angelman ${ }^{1}$ described three unrelated children with similar facial appearance, mental retardation, seizures, frequent prolonged episodes of laughter, and a jerky, ataxic gait which, he said, gave them a superficial resemblance to puppets. The condition has been recognised with increasing frequency and there are now 38 published cases. ${ }^{1-16}$ Though widely known as the "happy puppet syndrome', it has been suggested that the term Angelman syndrome is more appropriate for clinical use.

There have been previous reports of affected sibs $^{2-4}$ and a pair of monozygotic twins described by Hersh et al. ${ }^{5}$ We report an 11 year old girl and her five year old brother with the typical features of Angelman syndrome, together with three sporadic cases, and, in the light of these families' experience, we review the risk of recurrence in sibs.

\section{Case reports}

CASE 1 (FIGS 1 AND 2)

Case 1 was the first child of healthy unrelated parents of European origin, both under 20 years of age. The pregnancy was complicated by hypertension in the last week, but resulted in a normal delivery at 39 weeks' gestation, the baby weighing $3.3 \mathrm{~kg}$. She was a difficult baby to feed and developed stridor at one week which continued

Received for publication 14 November 1985

Revised version accepted for publication 10 February 1986.

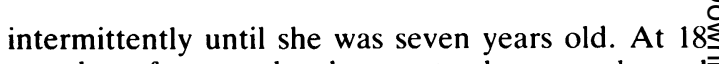
months of age, she began to have prolongedō outbursts of laughter and to have akinetic seizuresö which were controlled with carbamazepine. Herฉ̊ development has been slow; she first walked at three $\overrightarrow{0}$ years of age and at the age of 10 years 8 months had 3 not developed any speech, though she did understand simple commands.

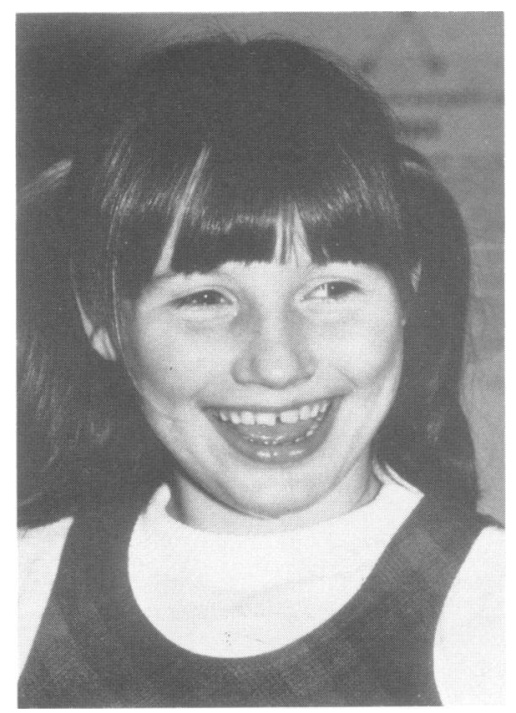

FIG 1 Case 1. 


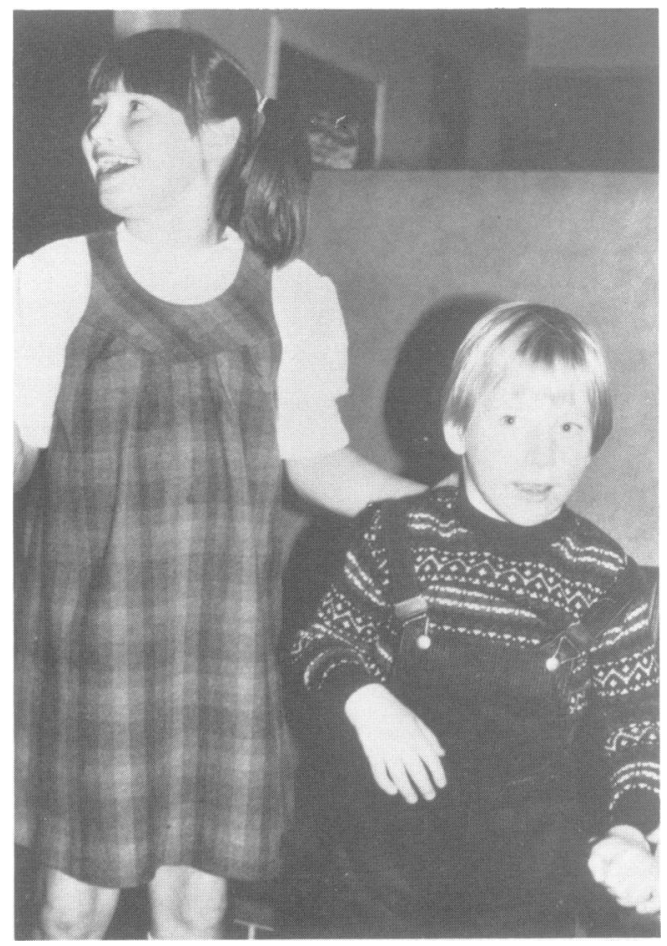

FIG 2 Cases 1 and 2.

On examination at 11 years she was easily excited with prolonged episodes of laughter and disruptive behaviour. She had a jerky, ataxic gait with a tendency to hold her arms abducted and flexed at the elbows, brachycephaly, prognathism, widely spaced teeth, and a tendency to dribble (fig 1). Her head circumference of $50.5 \mathrm{~cm}$ was on the 10 th centile. There were no ophthalmological abnormalities. Her EEG showed a background of slow activity, interrupted at frequent intervals by runs of generalised spike and wave activity.

CASE 2 (FIGS 3 AND 4)

Case 2, her only sib, was delivered by forceps at 32 weeks' gestation following an antepartum haemorrhage, weighing $2.04 \mathrm{~kg}$. There was no fetal distress and he did not develop any of the complications of prematurity. At 10 weeks of age, an inguinal hernia was repaired. Unprovoked outbursts of laughter began at 16 months of age. He started to have akinetic seizures at 18 months of age, which were controlled with carbamazepine. Motor development was slow and, when examined at the age of five years four months, he was found to have the typical 'puppet-like' gait and a preference for crawling.
Like his sister he had no speech and a developmental quotient of approximately 50. His head circumference of $49.5 \mathrm{~cm}$ was on the 10th centile.

The only ophthalmological abnormality was a right divergent strabismus. Like his sister, he had a relatively flat occiput, prognathism with widely spaced teeth, and a tendency to dribble. Muscular tone was slightly reduced but reflexes were abnormally brisk. Electroencephalography revealed

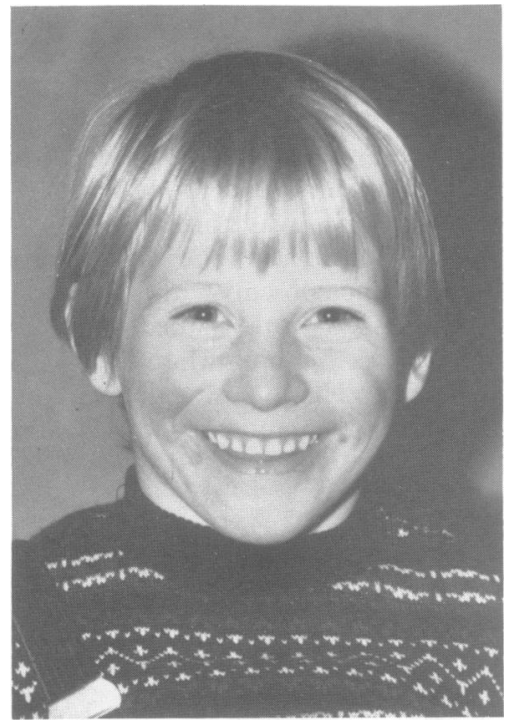

FIG 3 Case 2.

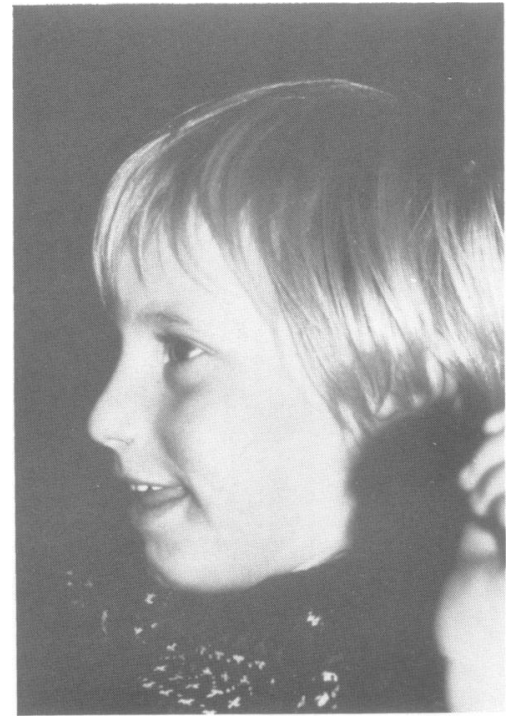

FIG 4 Case 2. 
generalised excess of slow activity but no epileptic activity.

Verbal presentation of the sib pair before the British Dysmorphology Group resulted in general agreement that the clinical picture was consistent with the diagnosis of Angelman syndrome.

CASE 3 (FIG 5)

Case 3 was the second child of unrelated parents in their middle twenties. He had been delivered by forceps. His brother was a normal six year old. As a baby case 3 was hypokinetic with frequent jerking of the arms. He sat unsupported at 10 months and began walking at 30 months. At three years two months of age he was still unable to feed himself and had not developed any speech. He had not had any seizures and his EEG was normal.

On clinical examination he was microcephalic (head circumference $46 \mathrm{~cm}$ ) with a flat occiput. He had a widely based, jerky, ataxic gait with arms raised and he was happier when able to keep his hand on a surface. His tone was normal but reflexes were brisk and both plantar responses were flexor. His right foot was held inverted.

CASE 4 (FIG 6)

Case 4 was the third child of healthy unrelated

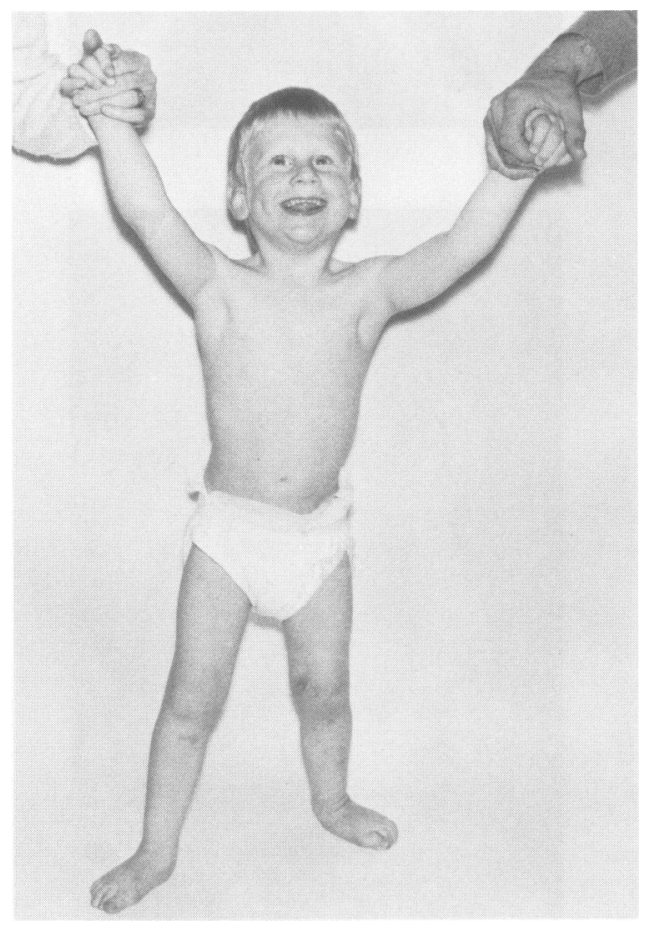

FIG 5 Case 3.

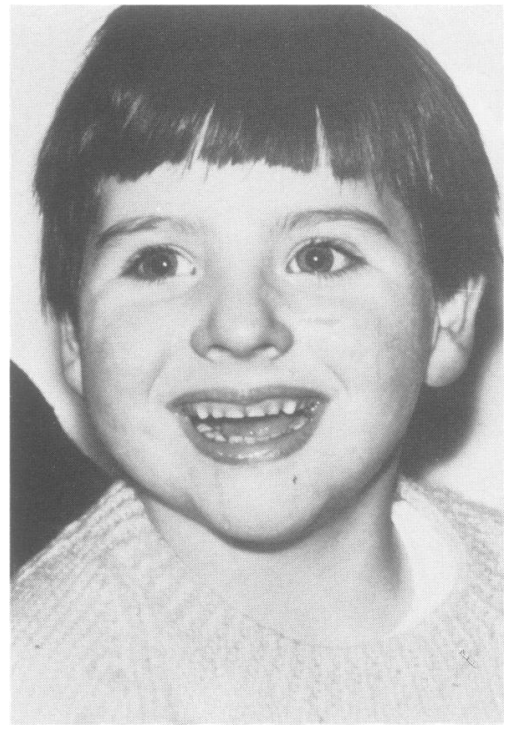

FIG 6 Case 4.

parents. Their first child had had a neural tubg defect and died shortly after birth. The second was healthy boy 12 months older than case 4 .

She was a floppy baby. Her mother described constant laughter being prominent even as a bab\$ She started to have right sided focal seizures at tw years of age. She sat at 10 months and bega田 walking at 36 months.

When examined at five years she had not devee oped any speech. She laughed constantly, had protruding tongue, prognathism, and widely space teeth. Her head circumference was $50.5 \mathrm{~cm}$ (50t] centile). Her gait was ataxic with a wide base an typical arm posture. Her tone and reflexes wers normal.

CASE 5 (FIG 7)

Case 5 was the first child of unrelated, health European parents. Pregnancy was normal angु birth weight was $3.4 \mathrm{~kg}$. His development seemed normal up to six months of age when, after a serieg of minor infections, the parents noted a failure tro progress and to gain weight. The mother also noted a flattening of the back of the head. He sat at 11 矢 months but failed to develop speech. At two years he started to smile and laugh often. At two yeaps four months he suffered his first fit. He continued to have frequent attacks of falling backwards with less frequent right sided attacks. His epilepsy was weㅐ controlled by clonazepam and carbamazepine.

On examination at two years four months, he was able to walk with support and bottom shuffle. He 


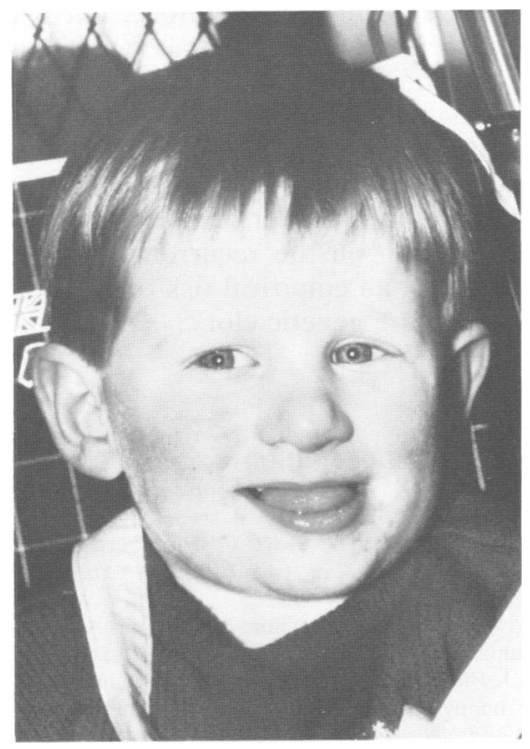

FIG 7 Case 5.

continued to be clumsy and unsteady with a tendency to hold his arms abducted with elbows flexed. He was hyperactive with some comprehension but no meaningful speech. He laughed frequently. Tone and reflexes were normal as were his fundi. An electroencephalogram was abnormal with a background of $6 \mathrm{~Hz}$ and intermittent 3 to $4 \mathrm{~Hz}$ delta, either frontally or posteriorly dominant. No definite seizure activity was apparent.

\section{Discussion}

All five of these cases have the typical features of Angelman syndrome: severe mental retardation with effective absence of speech, ataxia, seizures, typical arm posture, flat occiput, prognathism, widely spaced teeth, and tongue protrusion. Four of the five have spontaneous outbursts of laughter. Only two of the five were microcephalic. It has been suggested that microcephaly is pathognomonic. ${ }^{7}$ In fact, only 28 of the 38 published cases had overt microcephaly. Table 1 summarises the five cases described and the clinical features of the 38 published cases. ${ }^{1-16}$

The occurrence of the syndrome in a brother and sister raises the possibility of autosomal recessive inheritance. This was first proposed by Berg and Pakula in $1972 .{ }^{2}$ However, one of the two sibs in their report had epilepsy without any other features of the syndrome. In view of the importance of sib recurrence, this report should not be accepted as a definite second affected sib. In the report by Pashayan et al, ${ }^{3}$ one boy had all the features of the syndrome. His older brother had microcephaly, retardation, and epilepsy, but this was associated with spasticity and with a history of having suffered meningitis at four days of age. Again, we are unhappy to accept this as a definite recurrence of

TABLE 1 Clinical features of present cases and 38 published cases.

\begin{tabular}{|c|c|c|c|c|c|c|}
\hline & Case I & Case 2 & Case 3 & Case 4 & Case 5 & $\begin{array}{l}\text { Review of } 3 \dot{8} \\
\text { published cases } \\
\text { (refs } 1-16)\end{array}$ \\
\hline Age & 11 & 5 & 3 & 5 & 31 months & \\
\hline $\begin{array}{l}\text { Severe mental } \\
\text { retardation }\end{array}$ & Present & Present & Present & Present & Present & 38 \\
\hline Absence of speech & + & + & + & + & + & ( 3 no information) \\
\hline Seizures & $\begin{array}{l}\text { Akinetic. } \\
\text { started } 18 / 12\end{array}$ & $\begin{array}{l}\text { Akinetic. } \\
\text { started } 18 / 12\end{array}$ & None & $\begin{array}{l}\text { Right sided focal. } \\
\text { started } 24 / 12\end{array}$ & $\begin{array}{l}\text { Falling back or } \\
\text { right sided focal } \\
\text { from } 28 / 12\end{array}$ & 33 \\
\hline Laughter & + & + & Smiling & + & + & 32 \\
\hline Ataxia & + & + & + & + & + & $\begin{array}{l}29 \\
\text { (7 unable to walk) }\end{array}$ \\
\hline Typical arm posture & + & + & + & + & + & \\
\hline Tone & Decreased & Decreased & Normal & Normal & Normal & Decreased in 21 \\
\hline Reflexes & Brisk & Brisk & Brisk & Normal & Normal & Brisk in 32 \\
\hline Microcephaly & No & No & 3rd centile & No & Below 3rd centile & 28 \\
\hline Flat occiput & Present & Present & Present & Present & Present & 35 \\
\hline $\begin{array}{l}\text { Protruding } \\
\text { tongue }\end{array}$ & $\begin{array}{l}\text { Was a feature when } \\
\text { vounger }\end{array}$ & & & & & 30 \\
\hline Widely spaced teeth & $\begin{array}{l}\text { younger } \\
+\end{array}$ & $\begin{array}{l}+ \\
+\end{array}$ & $\begin{array}{l}+ \\
+\end{array}$ & $\begin{array}{l}+ \\
+\end{array}$ & $\begin{array}{l}+ \\
+\end{array}$ & $\begin{array}{l}22 \\
15\end{array}$ \\
\hline Prognathism & $\begin{array}{l}+ \\
+\end{array}$ & $\begin{array}{l}+ \\
+\end{array}$ & $\begin{array}{l}+ \\
+\end{array}$ & $\begin{array}{l}+ \\
+\end{array}$ & + & 24 \\
\hline EEG & $\begin{array}{l}\text { Slow. interrupted } \\
\text { by spike and wave } \\
\text { activity }\end{array}$ & $\begin{array}{l}\text { Generalised slow } \\
\text { activity }\end{array}$ & Normal & $\begin{array}{l}\text { Frequent bursts of } \\
\text { generalised sharp } \\
\text { and slow }\end{array}$ & $\begin{array}{l}\text { Intermittent } 3-4 \\
\text { Hz delta, often } \\
\text { rhythmic frontal or } \\
\text { posterior dominance }\end{array}$ & $\begin{array}{l}\text { Variety of } \\
\text { abnormalities } \\
\text { reported in } 24\end{array}$ \\
\hline
\end{tabular}


TABLE 2 Analysis of sibships*.

\begin{tabular}{lllll}
\hline & Earlier born & $\begin{array}{l}\text { Birth order } \\
\text { unknown }\end{array}$ & Later born & Total \\
\hline Published cases & 17 & 13 & $4(1)$ & 34 \\
Correspondence & - & - & 4 & 4 \\
This report & 2 & - & $1(1)$ & 3 \\
Total & $19(0) \dagger$ & $13(0)$ & $9(2)$ & $41(2)$ \\
\hline
\end{tabular}

${ }^{*}$ Excludes a MZ twin described by Hersh et al. ${ }^{5}$ a baby with craniosynostosis who died at one month. ${ }^{7}$ and a sib of our case 4 who died at birth due to neural tube defect.

tSibs described by Pashayan $e t a l^{3}$ and Berg and Pakula ${ }^{2}$ regarded as unaffected.

()Number in brackets=number of proven affected cases

Angelman syndrome within a family. The report by Kuroki et $a l^{4}$ is convincing, however, with typical features in both sibs, and taken with the present report establishes two definite examples of recurrence within a sibship.

Following a review of published reports, we wrote to the first authors of previous case reports. One author reported four normal later born children to add to the 34 already reported. The present report adds a further three, giving a total of 41 sibs with two affected (table 2). Nineteen sibs were born before the proband, and in 13 the birth order was not stated.

Only nine sibs, including the two with the syndrome, are known to have been born after the proband. It could be suggested, therefore, that taking only later born sibs a recurrence risk of $25 \%$ is valid. This is open to the obvious criticism that reporting bias in favour of affected sibs could greatly exaggerate their frequency. Conversely, the lack of reported later born sibs raises the possibility of voluntary limitation of family size because of the disruption caused by a child suffering from the Angelman syndrome. This hypothesis was supported by the families of two of the sporadic cases reported here. Although neither of them suffered particularly severe behavioural disorders or epilepsy compared to many cases of this syndrome, in both instances the parents had decided to limit their family to two children, each having had one previous normal child. Autosomal recessive inheritance cannot yet be dismissed, therefore, but is far from proven. It remains possible that occasional recu层 rences are the result of an unrecognised minof chromosomal abnormality. Karyotype analysis of our four cases has revealed no abnormality, thoug prometaphase banding has not been performed.

Until more information can be obtained in af unbiased fashion on the recurrence risk in Angef man syndrome, an empirical risk of $5 \%$ is appropr $\overrightarrow{5}$ ate for use in the genetic clinic.

\section{References}

1 Angelman H. Puppet children. A report on three cases. $D$

Med Child Neurol 1965;VII:681-8.
2 Berg J, Pakula Z. Angelman's happy puppet syndrome. Am: Dis Child 1972;123:295-8.

3 Pashayan H, Singer W. Bove C. Eisenberg E, Seto B. Th Angelman syndrome in two brothers. Am J Med Gent? 1982;13:295-8.

${ }^{4}$ Kuroki Y, Matsui I, Yamamoto Y, Ieshima A. Happy puppetsyndrome in two siblings. Hum Genet 1980:56:227-9.

5 Hersh J, Bloom A, Zimmerman A, et al. Behavioural correlat in the happy puppet syndrome. A characteristic profile? Det Med Child Neurol 1973;23:792-800).

- Mayo O, Nelson M, Townsend H. Case reports: three moß口 happy puppets. Dev Med Child Neurol 1973;15:63-74.

7 Williams C, Frias J. The Angelman's 'happy puppet' syndrom巳 Am J Med Genet 1982:11:453-60.

${ }^{\star}$ Bjerre I, Fagher B, Ryding E, Rose I. The Angelman or hap puppet syndrome. Acta Paediatr Scand 1984:73:398-402.

${ }^{4}$ Dooley J, Berg J, Pakula I, MacGregor D. The puppetlif syndrome of Angelman. Am J Dis Child 1981:135:621-4.

10 Elian M. Fourteen happy puppets, two new cases and a review Clin Pediatr 1975;14:902-8.

"Moore J, Jeavons P. The happy puppet syndrome-two ne cases and review of five previous cases. Neurol Pediatr 1973;IV:172-80.

12 Bower BD, Jeavons PM. The happy puppet syndrome. Arch Dis Child 1967:42:298-302.

13 Jeavons P. Moore J. The EEG and happy puppet syndromê Electroencephalogr Clin Neurophysiol 1972:33:346-8.

14 Pampiglione G, Marinez A. Evolution of Angelman's sy drome-follow up of three new cases. Electroencephalalogr Cline Neurophysiol 1983;56:72p.

15 Pele S, Levy J, Point G. Happy puppet syndrome ou syndronke du 'patin hilare'. Helv Paediatr Acta 1976;31:183-8.

is Halal F, Chagnon J. Le syndrome de la 'marionnette joyeuse Union Med Can 1976;105:1077-83.

Correspondence and requests for reprints to Dr Burn, Regional Genetics Advisory Service, $\mathbb{P}$ Claremont Place, Newcastle upon Tyne NE2 4AA 